\title{
Investigation of the Photodecomposition Rate Constant of Poly (Vinyl Chloride) Films Containing Organotin (IV) Complexes
}

\author{
Mustafa Ali ${ }^{1}$, Gamal A. El-Hiti ${ }^{2}$, Hanan Ibraheem ${ }^{1}$ and Emad Yousif ${ }^{1 *}$ \\ ${ }^{1}$ Department of Chemistry, College of Science, Al-Nahrain University, Baghdad-Iraq. \\ ${ }^{2}$ Cornea Research Chair, Department of Optometry, College of Applied Medical Sciences, King \\ Saud University, P.O. Box 10219, Riyadh 11433, Saudi Arabia. \\ Corresponding Author: emad_yousif@hotmail.com.
}

\begin{abstract}
The photodecomposition of poly(vinyl chloride), films containing organotin complexes $(0.5 \%$ by weight) was investigated. The photodecomposition rate constant was reduced significantly in the presence of organotin complexes compared to the blank PVC. The $\mathrm{Ph}_{3} \mathrm{SnL}$ complex was found to be the most effective additive in photostabilization of PVC films. The photodecomposition rate constant for PVC films containing triphenyltin(IV) was found to be $1.80 \times 10^{-3} \mathrm{sec}^{-1}$ compared to $4.75 \times 10^{-3} \mathrm{sec}^{-1}$ for PVC films in the absence of any additives. [DOI: $10.22401 /$ JNUS.20.3.04]
\end{abstract}

Keywords: Photodecomposition rate constant; Photostabilization; Organotin complexes; PVC films; Addtitives.

\section{Introduction}

Polymers are produced annually in huge quantities since they have various interesting industrial and medicinal applications [1-3]. Synthetic polymers are easy to produce at low coast using various convenient processes. There are 10,000 companies in the United State alone that are interested in manufacturing, processing and fabricating polymeric materials [4]. Poly(vinyl chloride) (PVC) is one of the most produced and consumed polymers worldwide [5]. It has various out door applications [6] such as construction materials [7-9]. However, long term exposure of PVC to sunlight and/or high temperature lead to its photo degradation [10]. As a result, changes in the polymer's physical and mechanical properties occur [11]. The defects or impurities within the PVC polymeric chain are the main reason for dehydrochlorination and/or photo oxidation that lead to formation of unsaturated centers [12-14]. Therefore, PVC should be protected against harsh weather conditions. Photostabilization of PVC can be established through the use of various additives. The most common additives are plasticizers [15], aromatics [16,17], heterocycles [18], Schiff base complexes $[19,20]$, metal complexes and inorganic salts.

Organotin complexes were used in various applications and in particular, for the stabilization of PVC [21]. In the present study, we investigated the photodecomposition rate constant $(k d)$ of PVC polymeric films containing organotin (IV) complexes on irradiation with UV light.

\section{Experimental}

\subsection{Materials}

Reagents and solvents were purchased from Sigma-Aldrich (Gillingham, UK) and have been used without further purification. PVC $(K$ value $=67$, degree of polymerization $=800)$ was obtained from Petkim Petrokimya (Istanbul, Turkey).

\subsection{Synthesis of organotin (IV) complexes}

Organotin (IV) complexes Fig.(2); $\mathrm{Ph}_{3} \mathrm{SnL}$, $\mathrm{Me}_{2} \mathrm{SnL}_{2}$ and $\left.\mathrm{Bu}_{2} \mathrm{SnL}_{2}\right)$ were synthesised as off white powders from reactions of furosemide with chlorotriphenylstannane, dichlorodimethylstannane or dibutyldichlorostannane in methanol, based on a literature procedure [22]. The structures of $\mathrm{Sn}(\mathrm{IV})$ complexes and their purities have been confirmed by the elemental analyses and various spectroscopic data and were in agreement with the ones reported [22]. 


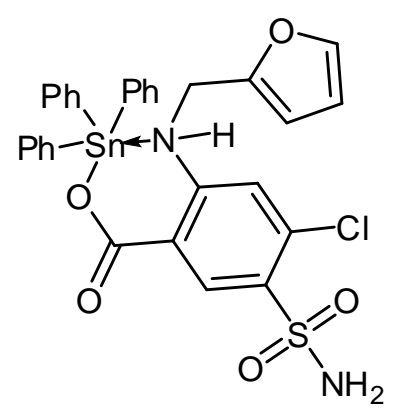

$\mathrm{Ph}_{3} \mathrm{SnL}$

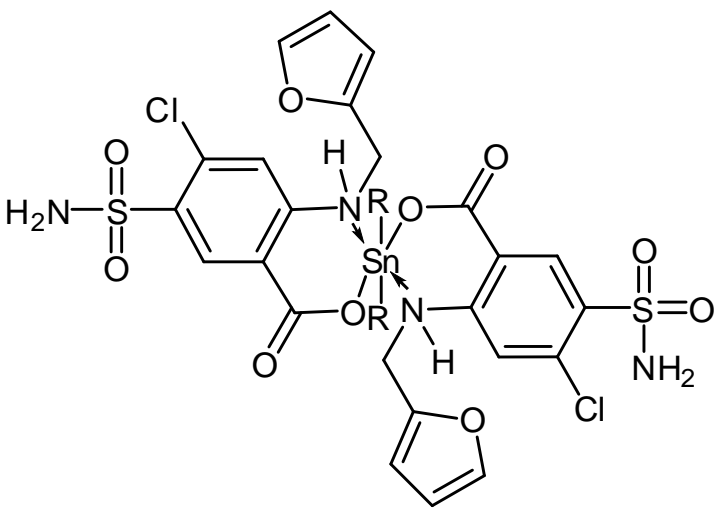

$\mathrm{R}=\mathrm{Me}, \mathrm{Bu}: \mathrm{Me}_{2} \mathrm{SnL}_{2} ; \mathrm{Bu}_{2} \mathrm{SnL}_{2}$

Fig.(2): Structures of organotin(IV) complexes.

\subsection{Films Preparation}

Commercial PVC in tetrahydrofuran $(5 \mathrm{~g} / 100 \mathrm{~mL})$ was re-precipitated with ethanol and dried for $24 \mathrm{~h}$ at $20^{\circ} \mathrm{C}$ under reduced presure. The organotin complexes $(0.5 \%$ by weight) were mixed with $\mathrm{PVC}$ at $20^{\circ} \mathrm{C}$ and were fixed using aluminum plate stands (Q-Panel Company, Homestead, FL, USA) [23]. The thickness of PVC films $(40 \mu \mathrm{m}$ thickness) was measured using a Digital Caliper Vernier (Kevelaer, Germany).

\subsection{Accelerated Testing Technique}

Irradiation $\left(290-360 \mathrm{~nm} ; \lambda_{\max }=313 \mathrm{~nm}\right)$ of PVC films was carried out using a standard procedure with an accelerated weather-meter QUV tester (Philips, Saarbrücken, Germany) $[19,20]$ for $300 \mathrm{~h}$.

\subsection{Photodegradation Rate (kd) of PVC Films using UV Spectrophotometer}

A Shimadzu UV-Vis 160A-Ultraviolet Spectrophotometer (Shimadzu Cooperation, Kyoto, Japan) was used to measure the changes in the UV-visible spectra of PVC films during irradiation $\left(\lambda_{\max }=313 \mathrm{~nm}\right)$ [24]. The photodecomposition rate constant $\left(k_{d}\right)$ of PVC films were calculated using Equation (1).

$$
\ln (a-x)=\ln a-k_{d} t
$$

where, $\quad a=A_{0}-A_{\infty}, \quad x=A_{0}-A_{t}$, $a=\mathrm{PVC}$ concentration before irradiation and $x=$ change in PVC concentration at time $t$ during irradiation as shown in Equation (2), $A_{0}=$ the absorption intensity of the PVC at $t_{0}$, $A_{\infty}=$ the absorption intensity at $t_{\infty}$ and $A_{t}=$ the absorption intensity after irradiation time $t$.

$$
a-x=A_{0}-A_{\infty}-A_{0}+A_{t}=A_{t}-A_{\infty}
$$

Equation (3) was obtained by substituting $a-x$ in Equation (1) by its value in Equation (2).

$$
\ln \left(A_{t}-A_{\infty}\right)=\ln \left(A_{0}-A_{\infty}\right)-k_{d} t
$$

The plot of $\ln \left(A_{t}-A_{\infty}\right)$ versus irradiation time $(t)$ gives straight line in which the slope equal $k_{d}$. The photodecomposition of PVC follows a first order kinetics [25].

\section{Results and Discussion}

The effect of organotin (IV) complexes $\left(\mathrm{Me}_{2} \mathrm{SnL}_{2}, \mathrm{Bu}_{2} \mathrm{SnL}_{2}\right.$ and $\left.\mathrm{Ph}_{3} \mathrm{SnL}\right)$ on the PVC films photodecomposition was investigated. The PVC films (40 $\mu \mathrm{m}$ thickness) containing organotin (IV) complexes $(0.5 \%$ by weight) were irradiated with a UV light $\left(\lambda_{\max }=313 \mathrm{~nm}\right)$ for $300 \mathrm{~h}$. The irradiation led to a clear change in PVC films and decomposition took place. The plot of $\ln \left(A_{t}-A_{\infty}\right)$ against irradiation time $(t)$ gave a straight line. The graphs showed first order kinetics in which the slope equalled the decomposition rate constant $(k d)$ for PVC films. Fig.(3) shows the change in $\ln \left(A_{t}-A_{\infty}\right)$ against irradiation time $(t)$ for PVC films in the absence any additives. Figures 4-6 show the changes in the $\ln \left(A_{t}-A_{\infty}\right)$ against irradiation time for PVC films containing organotin (IV) additives ( $0.5 \%$ by weight) as stabilizers for PVC films on irradiation with light. 


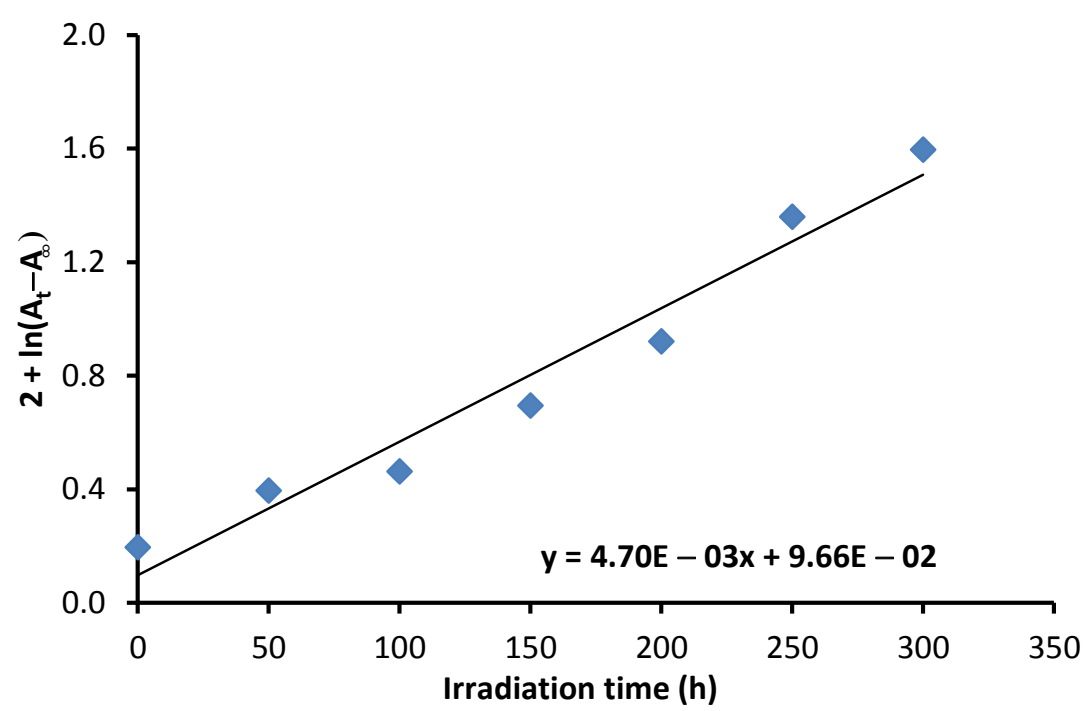

Fig.(3): Changes in $\ln \left(A_{t}-A_{\infty}\right)$ for PVC (blank) film with irradiation time.

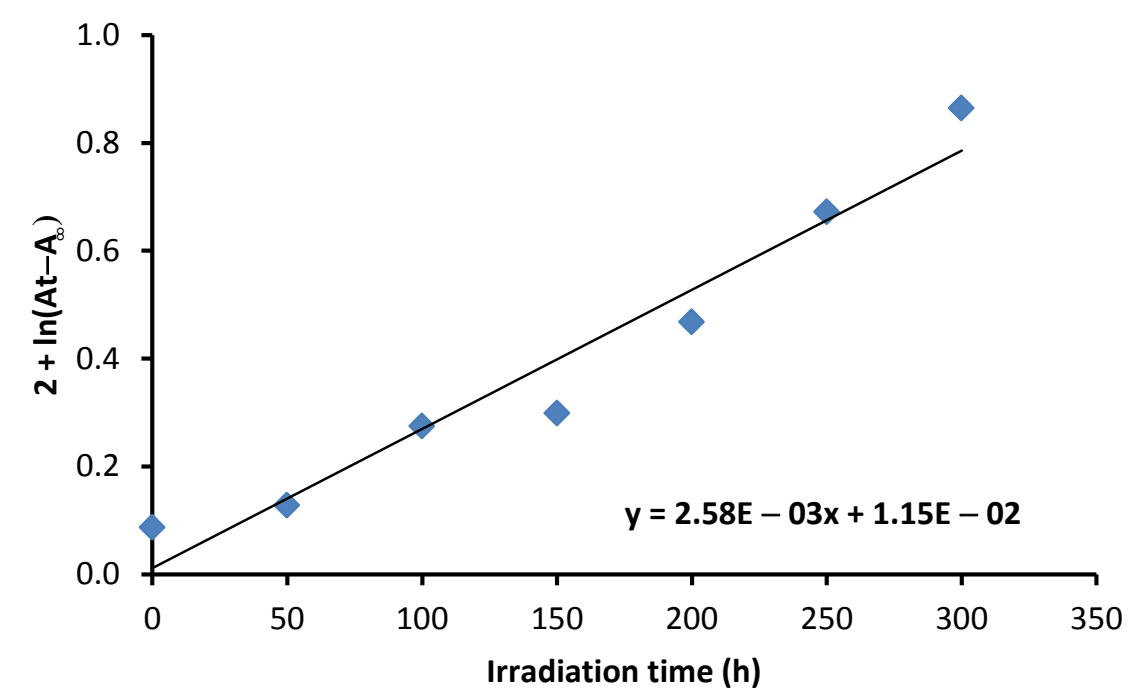

Fig.(4): Changes in $\ln \left(A_{t}-A_{\infty}\right)$ for PVC film containing $\mathrm{Me}_{2} \mathrm{SnL}_{2}$ with irradiation time.

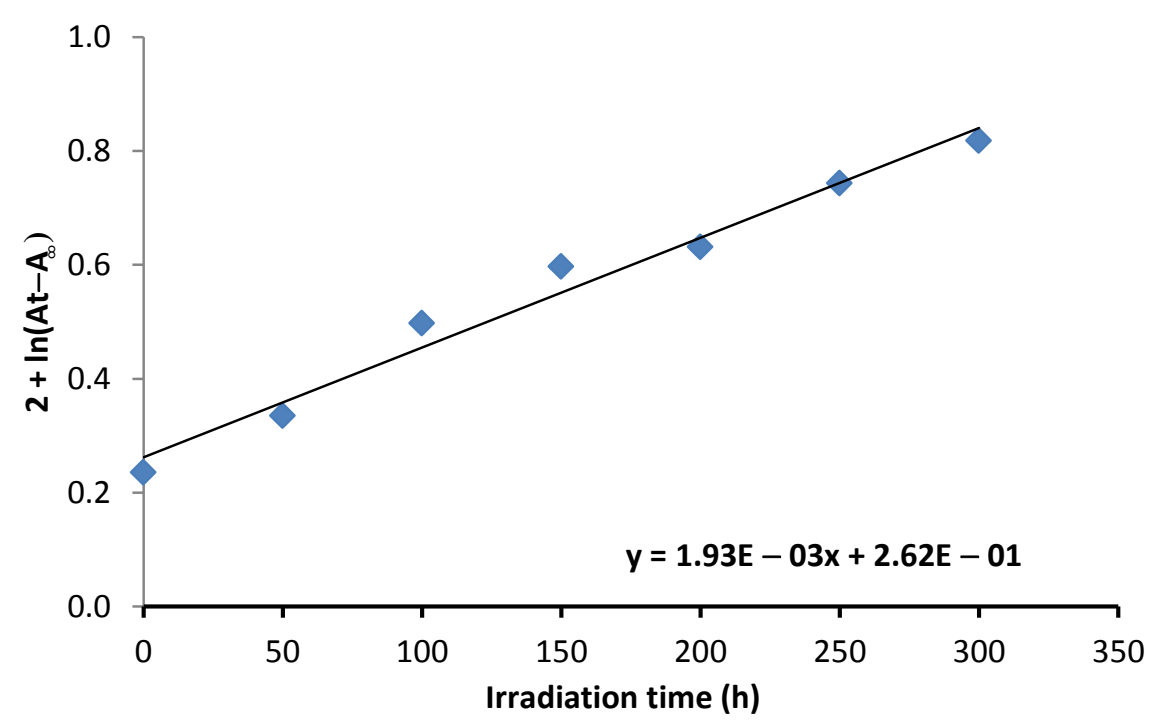

Fig.(5): Changes in $\ln \left(A_{t}-A_{\infty}\right)$ for PVC film containing $B u_{2} S n L_{2}$ with irradiation time. 


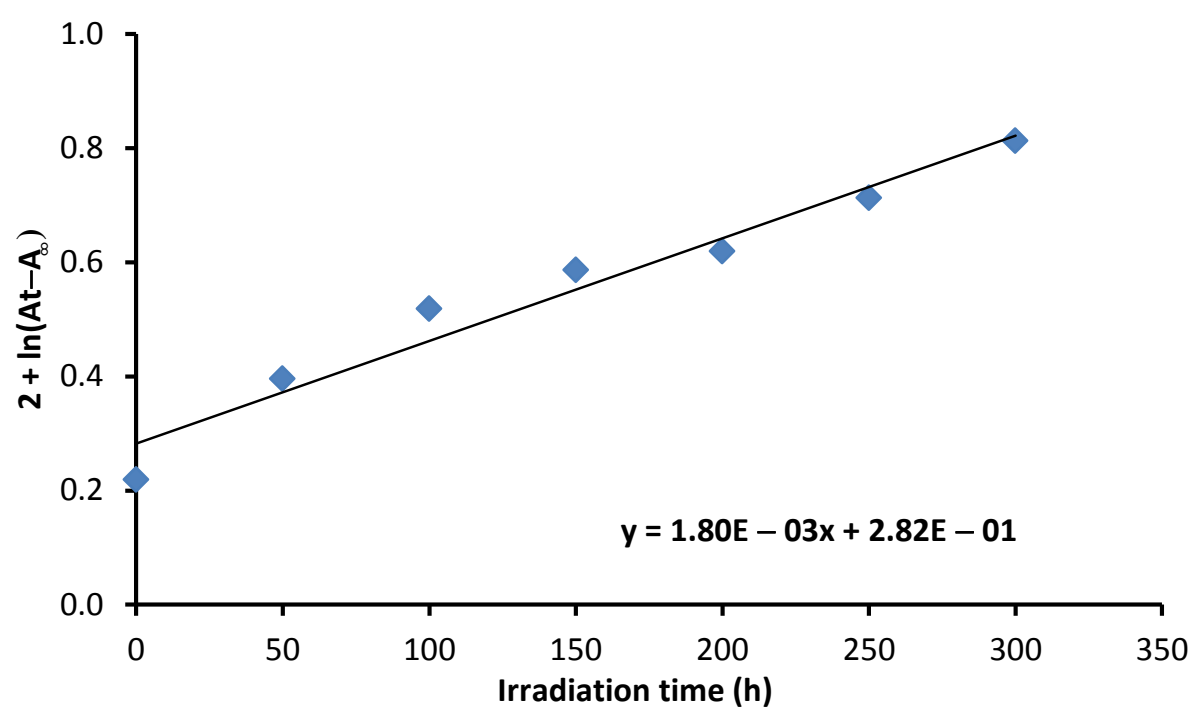

Fig.(6): Changes in $\ln \left(A_{t}-A_{\infty}\right)$ for PVC film containing $P h_{3} S n L$ with irradiation time.

Table (1)

Photodecomposition rate constant (kd) for PVC films on UV irradiation (300 h).

\begin{tabular}{|c||c|}
\hline PVC film & $K_{d}\left(\mathrm{sec}^{-1}\right)$ \\
\hline \hline PVC $($ blank $)$ & $4.70 \times 10^{-3}$ \\
\hline \hline PVC $+\mathrm{Me}_{2} \mathrm{SnL}_{2}$ & $2.58 \times 10^{-3}$ \\
\hline $\mathrm{PVC}+\mathrm{Bu}_{2} \mathrm{SnL}_{2}$ & $1.93 \times 10^{-3}$ \\
\hline $\mathrm{PVC}+\mathrm{Ph}_{3} \mathrm{SnL}$ & $1.80 \times 10^{-3}$ \\
\hline
\end{tabular}

The first order photodecomposition rate constant $\left(k_{d}\right)$ for PVC films containing organotin (IV) complexes (0.5 wt \%) along with that for PVC (blank) is shown in Table (1). Table (1) and Figs. (3-6) show that the rate constant $\left(k_{d}\right)$ values are sensitive to the presence of organotin (IV) complex and its type. The PVC photodecomposition rate constant for PVC films was high $\left(4.70 \times 10^{-3} \mathrm{sec}^{-1}\right)$ in the absence of any additives. Such rate constant has been reduced significantly $\left(1.80-2.58 \times 10^{-3} \mathrm{sec}^{-1}\right) \quad$ when organotin (IV) complexes were used as additives. The photostabilization of PVC in the presence of organotin (IV) complexes follow the order of $\mathrm{Ph}_{3} \mathrm{SnL}>\mathrm{Bu}_{2} \mathrm{SnL}_{2}>\mathrm{Ph}_{3} \mathrm{SnL}$. The triphenyl (IV) complex was the most efficent than the other organotin complexes in photostabilization of PVC films presumely due to the reseonce of the extra phenyl group (i.e. acted as a better radical scavenger) [22].

Clearly, organotin (IV) complexes have acted as photostabilizers for the photostabilization of PVC films. The photodecomposition rate constant was highest for PVC (blank) and lowest in the presence of triphenyltin (IV) complex. Such photostabilizers could act as $\mathrm{HCl}$ scavengers, peroxide decomposers, primary stabilizers, UV absorbers and radical scavengers [26-28].

\section{Conclusions}

The photodecomposition rate constants for PVC films containing organotin (IV) complexes have been reduced significantly compared to the PVC in the absence of any additives. The photodecomposition rate constant for PVC films containing organotin (IV) was $1.80-2.58 \times 10^{-3} \mathrm{sec}^{-1}$ compared to $4.75 \times 10^{-3} \mathrm{sec}^{-1}$ for the blank PVC film. Triphenyltin (IV) complex was the most effective complex towards the photostabilization of PVC. Such complex can be used as a PVC photostabilizer for long term protection from sunlight and/or UV radiation. 


\section{Acknowledgments}

The authors extend their appreciation to the Department of Chemistry, College of Science, Al-Nahrain University and to the Deanship of Scientific Research at King Saud University for its funding for this research through the research group project RGP-239 and to the for continued support.

\section{References}

[1] Carraher E., Giant Molecules: Essential Materials for Everyday Living and Problem Solving, 2nd ed., John Wiley \& Sons, New Jersey: Hoboken, 2003.

[2] Carraher E., Polymer Chemistry, 6th ed., Marcel Dekker Inc.: New York, 2003.

[3] Craver D., Carraher E., Applied Polymer Science: 21st Century, 1st ed., Elsevier: New York, 2000.

[4] Chemistry Explained, Foundation and Applications: Synthetic Polymers. Available: http://www.chemistryexplained.com/PlPr/Polymers-Synthetic.html [Accessed on 08 October 2016].

[5] Huang Z., Ding A., Guo H., Lu G., Huang, $\mathrm{X}$., Construction of nontoxic polymeric UV-absorber with great resistance UVphotoaging, Sci. Rep., 6, doi:10.1038/srep25508, 2016.

[6]Saeki Y., Emura T., Technical progresses for PVC production, Prog. Polym. Sci., 27, 2055-2131, 2002.

[7] Zhang X., Zhao T., Pi H., Guo S., Mechanochemical preparation of a novel polymeric photostabilizer for poly(vinyl chloride), J. Appl. Polym. Sci., 116, 30793086, 2010.

[8] Real P., Ferraria M., Botelho de Rego M., Comparison of different photo-oxidation conditions of poly(vinyl chloride) for outdoor applications, Polym. Test., 27, 743751, 2008.

[9] Nicholson W., The Chemistry of Polymers, $3^{\text {rd }}$ ed.; RSC Publications: Cambridge, UK., 2012.

[10] Starnes W., Structural and mechanistic aspects of the thermal degradation of poly(vinyl chloride), Prog. Polym. Sci., 27, 2133-2170, 2002.
[11] Yousif E., Hasan A., El-Hiti G., Spectroscopic, Physical and Topography of Photochemical Process of PVC Films in the Presence of Schiff Base Metal Complexes, polym. 8, 204; doi:10.3390/polym8060204, 2016.

[12] Fahmy M., Mohamed R., Mohamed A. Novel antimicrobial organic thermal stabilizer and co-Stabilizer for rigid PVC, Molecules, 17, 7927-7940, 2012.

[13] Iván B., Kennedy P., Kélen T., Tüdòs F., Nagy T., Turcsanyi B., Degradation of PVCs obtained by controlled chemical dehydrochlorination, J. Polym. Sci. A: Polym. Chem., 21, 2177-2188, 1983.

[14] Caraculacu A. Bezdade C., Structure of branching in PVC, J. Polym. Sci. A: Polym. Chem., 8, 1239-1246, 1970.

[15] Yousif E., Haddad R., El-Hiti G., Yusop R., Spectroscopic and photochemical stability of polystyrene films in the presence of metal complexes. J. T. U. SCI., http://dx.doi.org/doi:10.1016/j.jtusci.2017.0 3.002 .

[16] Sabaa W., Oraby H., Abdel Naby S., Mohamed R., Anthraquinone derivatives as organic stabilizers for rigid poly(vinyl chloride) against photo-degradation, Eur. Polym. J., 41, 2530-2543, 2005.

[17] Tomohito K., Masahiko O., Guido G., Tadaaki M., Toshiaki Y., Antibacterial effect of thiocyanate substituted poly (vinyl chloride), J. Polym. Res., 18, 945-947, 2011.

[18] Balakit A., Ahmed A., El-Hiti G., Smith K., Yousif E., Synthesis of new thiophene derivatives and their use as photostabilizers for rigid poly(vinyl chloride, Int. J. Polym. Sci., doi:10.1155/2015/510390, 2015.

[19] Ahmed D., El-Hiti G., Hameed A., Yousif E., Ahmed A., New Tetra-Schiff Bases as Efficient Photostabilitizers for Poly(vinyl Chloride), doi:10.3390/molecules22091506, 2017

[20] Yousif E., El-Hiti G., Hussain Z., Altaie A., Viscoelastic, spectroscopic and microscopic study of the photo irradiation effect on the stability of PVC in the presence of sulfamethoxazole Schiff's bases, Polymers, 7, 2190-2204, 2015.

[21] Yousif E., Salimon J., Salih, J., New photostabilizers for PVC based on some 
diorganotin(IV) complexes, J. Saudi Chem. Soc., 19, 133-141, 2015.

[22] Ali M., El-Hiti G., Yousif E., Photostabilizing efficiency of poly(vinyl chloride) in the presence of organotin(IV) complexes as photostabilizers, Molecules, 21, 9, doi:10.3390/molecules21091151, 2016.

[23] Yousif E., Hameed A., Rasheed R., Mansoor H., Farina Y., Graisa A., Salih N., Salimon J., Synthesis and photostability study of some modified poly(vinyl chloride) containing pendant benzothiazole and benzimidozole ring, Int. J. Chem., 2, 65-80, 2010.

[24] Aliwi S., Najim T., Naief O., Photostabilization of poly (vinyl chloride) using natural products, J. Coll. Edu., 1, 357-390, 2011.

[25] Khan R., Tawakkul M., Sayeed A., Faustino P., Khan M., Stability characterization, kinetics and mechanism of degradation of dantrolene in aqueous solution: effect of $\mathrm{pH}$ and temperature, Pharmacol. Pharm., 3, 281-290, 2012.

[26] Folarin M., Sadiku R., Thermal stabilizers for poly(vinyl chloride): A review," Int. J. Phys. Sci., 6, 4323-4330, 2011.

[27] Deanin D., Reynolds H., Ozcayir Y., Thermal stabilization of polyvinyl chloride by group II metal laurates, J. Appl. Polym. Sci., 13, 1247-1252, 1969.

[28] Shyichuk V., and White R., Analysis of chain-scission and crosslinking rates in the photo-oxidation of polystyrene, J. Appl. Polym. Sci., 77, 3015-3023, 2000. 